\title{
Catechol-O-Methyltransferase Inhibition Improves Set- Shifting Performance and Elevates Stimulated Dopamine Release in the Rat Prefrontal Cortex
}

\author{
E. M. Tunbridge, ${ }^{1}$ D. M. Bannerman, ${ }^{2}$ T. Sharp, ${ }^{3}$ and P. J. Harrison ${ }^{1}$ \\ ${ }^{1}$ Department of Psychiatry, University of Oxford, Oxford, United Kingdom, OX3 7JX, 2Department of Experimental Psychology, University of Oxford, \\ Oxford, OX1 3UD, United Kingdom, and 3Department of Pharmacology, University of Oxford, Oxford, OX1 3QT, United Kingdom
}

\begin{abstract}
The Val ${ }^{158}$ Met polymorphism of the human catechol-O-methyltransferase (COMT) gene affects activity of the enzyme and influences performance and efficiency of the prefrontal cortex (PFC); however, although catecholaminergic neurotransmission is implicated, the underlying mechanisms remain elusive because studies of the role of COMT in PFC function are sparse. This study investigated the effect of tolcapone, a brain-penetrant COMT inhibitor, on a rat model of attentional set shifting, which is dependent on catecholamines and the medial PFC (mPFC). Additionally, we investigated the effect of tolcapone on extracellular catecholamines in the mPFC using microdialysis in awake rats. Tolcapone significantly and specifically improved extradimensional (ED) set shifting. Tolcapone did not affect basal extracellular catecholamines, but significantly potentiated the increase in extracellular dopamine (DA) elicited by either local administration of the depolarizing agent potassium chloride or systemic administration of the antipsychotic agent clozapine. Although extracellular norepinephrine (NE) was also elevated by local depolarization and clozapine, the increase was not enhanced by tolcapone.

We conclude that COMT activity specifically affects ED set shifting and is a significant modulator of mPFC DA but not NE under conditions of increased catecholaminergic transmission. These data suggest that the links between COMT activity and PFC function can be modeled in rats and may be specifically mediated by DA. The interaction between clozapine and tolcapone may have implications for the treatment of schizophrenia.
\end{abstract}

Key words: tolcapone; clozapine; catecholamine; norepinephrine; working memory; antipsychotic

\section{Introduction}

Catechol-O-methyltransferase (COMT) metabolizes catecholamines (Männisto and Kaakkola, 1999). The human COMT gene contains a polymorphism ( $\left.\mathrm{Val}{ }^{158} \mathrm{Met}\right)$ that influences enzyme activity ex vivo, the wild-type $\mathrm{Val}^{158}$ having threeto fourfold greater activity than Met ${ }^{158}$ (Lachman et al., 1996). The Met ${ }^{158}$ allele has been linked with better performance and efficiency on prefrontal cortex (PFC)-dependent tasks such as the Wisconsin card sorting task (WCST) (Egan et al., 2001). The link between COMT and PFC function may extend to schizophrenia, which is associated with a COMT haplotype that includes the Val ${ }^{158}$ Met polymorphism (Shifman et al., 2002), and possibly with the Val ${ }^{158}$ allele itself (Egan et al., 2001). COMT may play a particular role in regulating PFC dopamine (DA), given the sparsity of cortical DA transporters compared with the striatum (Sesack et al., 1998; Egan et al., 2001).

Other species lack an equivalent polymorphism, and the ac-

Received Jan. 26, 2004; revised April 27, 2004; accepted April 27, 2004.

This work was supported by a Wellcome studentship awarded to E.M.T. Tolcapone was kindly supplied by Roche Pharmaceuticals. We are grateful to D. Jones, J. Gartlon, M. Le Masurier, and K. Jennings for advice and assistance, and to E. Borroni, N. Rawlins, R. Rogers, and D. Weinberger for helpful discussions.

Correspondence should be addressed to Elizabeth Tunbridge, Neurosciences Building, University Department of Psychiatry, Warneford Hospital, 0xford, 0xfordshire, 0X3 7JX, UK. E-mail: elizabeth.tunbridge@psych.ox.ac.uk. DOI:10.1523/JNEUROSCI.1124-04.2004

Copyright $\odot 2004$ Society for Neuroscience $\quad$ 0270-6474/04/245331-05\$15.00/0 tivity of rat COMT resembles the human Val ${ }^{158}$ form (Lachman et al., 1996). Given the link between the low-activity Met ${ }^{158}$ allele and better PFC performance, it is of interest to determine whether reducing COMT activity in rats has similar effects. Tolcapone, a selective, brain-penetrant COMT inhibitor (Zürcher et al., 1990; Ceravolo et al., 2002), provides a pharmacological way to achieve this goal. Indeed, preliminary data suggest that tolcapone improves memory performance (Gaspirini et al., 1997; Khromova et al., 1997, Liljequist et al., 1997). These data are inconclusive, however, and there has been no evaluation of the effects of tolcapone on PFC catecholamines or in rodent tasks more formally similar to those used to assess human PFC function (e.g., WCST). Recently, a paradigm has been developed that assesses extra-dimensional (ED) set shifting, a cardinal feature of the WCST (Roberts et al., 1988), in rats (Birrell and Brown, 2000). It evaluates an animal's ability to shift attention from one dimension of a complex perceptual stimulus to another [e.g., odor to texture; an ED shift (EDS)] as well as evaluating discrimination learning, set formation, and reversal learning.

ED shifting is dependent on the PFC in primates (Dias et al., 1996b) and humans (Nagahama et al., 2001; Manes et al., 2002) and the medial PFC (mPFC) in rats (Birrell and Brown, 2000). Like other PFC-mediated functions, ED shifting is modulated by DA (Roberts et al., 1994; Rogers et al., 1999; Crofts et al., 2001). There is an inverted U-shaped relationship between DA and PFC 
Table 1. Set-shifting exemplars used and example of discriminations, with rewarded exemplars highlighted

\begin{tabular}{lll}
\hline Discrimination & Odor pair & Medium pair \\
\hline SD & & $\underline{\text { Ground tea/leaf tea }}$ \\
CD & Cinnamon/cumin & $\underline{\text { Ground tea/leaf tea }}$ \\
Rev1 & Cinnamon/cumin & Ground tea/leaf tea \\
IDS & Mint/paprika & Fine sawdust/wood shavings \\
Rev2 & Mint/paprika & Fine sawdust/wood shavings \\
EDS & Cloves/thyme & Shredded tissue paper/tissue paper balls \\
$\operatorname{Rev3}$ & Cloves/thyme & Shredded tissue paper/tissue paper balls
\end{tabular}

SD, Simple discrimination; CD, compound discrimination; Rev, reversal; IDS, intradimensional shift; EDS, extradimensional shift.

performance, the latter being impaired by either blockade (Williams and Goldman-Rakic, 1995; Ragozzino, 2002) or overstimulation (Zahrt et al., 1997) of DA D1 receptors. ED shifting may also be impaired in states of DA depletion (Downes et al., 1989) (but see Roberts et al., 1994). Overall, these data suggest that the beneficial effect of lower COMT activity on PFC performance (whether genetic or pharmacologically induced) is caused by enhanced DA availability. To help clarify this issue, we have studied the effects of COMT inhibition on set shifting and on $\mathrm{mPFC}$ catecholamines at baseline and under conditions of increased efflux as would be expected during performance of an mPFCdependent task (Watanabe et al., 1997; Wilkinson et al., 1998).

\section{Materials and Methods}

Animals and drugs. Male Sprague Dawley rats (220 gm for behavioral testing, 270-300 gm for microdialysis; Harlan-Olac, Bicester, UK) were housed in groups of four (behavioral testing) or six (microdialysis). Experiments were conducted during the light phase of a $12 \mathrm{hr}$ light/dark cycle. Rats used for behavioral testing were maintained on a restricted diet $(90 \%$ free-feeding weight) with water available ad libitum in the home cage. Microdialysis rats were given food and water ad libitum. All experiments were conducted in accordance with the UK Animals (Scientific Procedures) Act 1986 and associated Home Office Guidelines.

Tolcapone, a COMT inhibitor with no effect on other enzymes involved in synthesis or catabolism of the amines (Zürcher et al., 1990), was suspended in $0.9 \%$ saline with a few drops of Tween 80 and administered intraperitoneally at a dose of $30 \mathrm{mg} / \mathrm{kg}$. This dose significantly inhibits COMT (Acquas et al., 1992). Clozapine (Sigma, Poole, UK) was dissolved in glacial acetic acid and administered subcutaneously in $0.9 \%$ saline containing $5 \%$ glucose (w/v, pH 6) at a dose of $10 \mathrm{mg} / \mathrm{kg}$.

Attentional set-shifting task. Behavioral testing was performed according to Birrell and Brown (2000) with minor modifications. Briefly, the testing apparatus consisted of a home cage with one end divided into two equal sections forming two choice chambers to which access could be blocked via removable doors. Rats were habituated to the apparatus and then trained to dig for a food reward (one-fourth Honey Nut Loop, Kellogg, Manchester, UK) in ceramic bowls, which were located centrally in the choice chambers, containing an inaccessible reward in the base to act as an odor mask. Once habituated, rats performed two simple discriminations based on odor (lemon vs lavender sawdust) and digging medium (pebbles vs sand) to a criterion of six consecutive correct trials. On the following day, rats were administered either tolcapone $(30 \mathrm{mg} /$ $\mathrm{kg}$ ) or vehicle and replaced in their home cage. After $1 \mathrm{hr}$ they were tested to a criterion of six consecutive correct trials on a series of discriminations in the following order: simple discrimination, compound discrimination, reversal, intradimensional shift, reversal, EDS, and reversal. On each trial the stimuli differed in both the relevant and irrelevant dimensions. Incorrect choices resulted in no food reward. Rats took an average of $3 \mathrm{hr} 36 \mathrm{~min}$ to complete the task (COMT inhibition levels remain high for $8 \mathrm{hr}$ after tolcapone administration) (Acquas et al., 1992), and the average intertrial interval was $1 \mathrm{~min} 6 \mathrm{sec}$. The exemplars used were piloted for discriminability, and an example set of discriminations is given in Table 1. Drug and vehicle groups were counterbalanced for the rewarded stimulus, the shift pattern (odor to medium or medium to odor), performance on habituation day simple discriminations, and whether the animal was tested in the morning or afternoon. The experimenter was blind as to whether animals had received drug or vehicle.

Microdialysis. Guide cannulas were stereotactically implanted above mPFC under halothane anesthesia. After surgery rats were housed in pairs in recovery cages. After a 5-7 d recovery period, concentric microdialysis probes ( $4 \mathrm{~mm}$ tip length) were implanted into $\mathrm{mPFC}$ under light halothane anesthesia $[+3.2 \mathrm{~mm}$ rostrocaudal, $+0.7 \mathrm{~mm}$ mediolateral from bregma, $-5.8 \mathrm{~mm}$ dorsoventral from dura surface) (Paxinos and Watson, 1986)]. The probes were secured with dental cement and connected to a perfusion pump (CMA/100, CMA Microdialysis, Sunderland, UK) via a liquid swivel system (CMA/120 system for freely moving animals; CMA Microdialysis). Animals were placed in hemispherical Perspex bowls to recover, and the probe was perfused continuously with artificial CSF at a rate of $2 \mu \mathrm{l} / \mathrm{min}$. Perfusate samples were collected every 20 min until a stable baseline of at least three samples was achieved (typically $2-3 \mathrm{hr}$ after probe implantation), at which point the tolcapone or vehicle was administered and dialysates were collected for an additional $4 \mathrm{hr}$. In separate experiments, tolcapone was administered $2 \mathrm{hr}$ before challenge with either systemic clozapine $(10 \mathrm{mg} / \mathrm{kg})$ or local perfusion of the dialysis probe with potassium chloride $(56 \mathrm{~mm}$ ) for $20 \mathrm{~min}$ to investigate their effect on evoked catecholamine release. Each drug treatment group contained six to eight animals.

Measurement of dialysate catecholamines, homovanillic acid, and $D O P A C$. Immediately after collection, dialysates were analyzed for extracellular dopamine $\left([\mathrm{DA}]_{\mathrm{EX}}\right)$, norepinephrine $\left([\mathrm{NE}]_{\mathrm{EX}}\right)$, DOPAC $\left([\mathrm{DOPAC}]_{\mathrm{EX}}\right)$, and homovanillic acid (HVA) $\left([\mathrm{HVA}]_{\mathrm{EX}}\right)$ using HPLC with electrochemical detection. Catecholamines and metabolites were separated with a Varian Microsorb $100 \mathrm{C}_{18}$ column $(4.6 \times 100 \mathrm{~mm}, 3 \mu \mathrm{m}$ $\mathrm{C}_{18}$ Microsorb particles; Anachem, Luton, UK) and a mobile phase containing $0.13 \mathrm{M} \mathrm{NaH}_{2} \mathrm{PO}_{4} \cdot \mathrm{H}_{2} \mathrm{O}, 3.2 \mathrm{~mm} 1$-octanesulfonic acid sodium salt, $0.8 \mathrm{~mm}$ EDTA, and $15 \%(\mathrm{v} / \mathrm{v})$ methanol, $\mathrm{pH} \mathrm{3.5}$, at a flow rate of 1 $\mathrm{ml} / \mathrm{min}$. A glassy carbon working electrode $(+0.7 \mathrm{~V}$ vs Ag/ $\mathrm{AgCl}$ reference electrode; BAS Instruments, Kenilworth, UK) was used for electrochemical detection (BAS LC-48 amperometric detector; BAS Instruments). Average basal $[\mathrm{DA}]_{\mathrm{EX}}$ levels were $5 \times$ HPLC detection limits.

Data analysis. The number of trials and errors to criterion for each discrimination during the behavioral task were analyzed using two-way repeated measures ANOVA with simple main effects post hoc tests. Analysis of both data sets gave essentially the same results, so only the trials to criterion data are presented.

Microdialysis data are expressed as a percentage of the baseline value, calculated as the mean amount of catecholamine or metabolite in the last three samples preceding the drug challenge. The effect of drug challenge was analyzed within groups using one-way ANOVA with repeated measures. Between groups analysis was performed using two-way ANOVA with repeated measures and least significant difference (LSD) post hoc comparisons.

\section{Results}

\section{Effect of COMT inhibition on set shifting}

Animals treated with $30 \mathrm{mg} / \mathrm{kg}$ tolcapone performed significantly better on the EDS than controls (Fig. 1). There was an effect of drug group $\left(F_{(1,12)}=5.7 ; p<0.05\right)$ and a significant interaction between drug group and discrimination $\left(F_{(5,60)}=3.1 ; p<0.05\right)$. This interaction was attributable entirely to a significant improvement on the EDS in the tolcapone group $\left(F_{(1,72)}=15.3 ; p<\right.$ $0.001)$. There were no group differences on any of the other discriminations $(F$ values $<1.8)$ (Fig. 1$)$, including the final reversal stage ( $t$ test; $p>0.1$ ), which was omitted from the ANOVA because four animals (three vehicle treated, one tolcapone treated) failed to complete it. There was an effect of discrimination $\left(F_{(5,60)}=38.2 ; p<0.0001\right)$; however, there was no effect of counterbalance on performance $\left(F_{(3,12)}=2.0 ; p>0.1\right)$, nor were any of the other interactions significant $(F$ values $<1.8)$. 


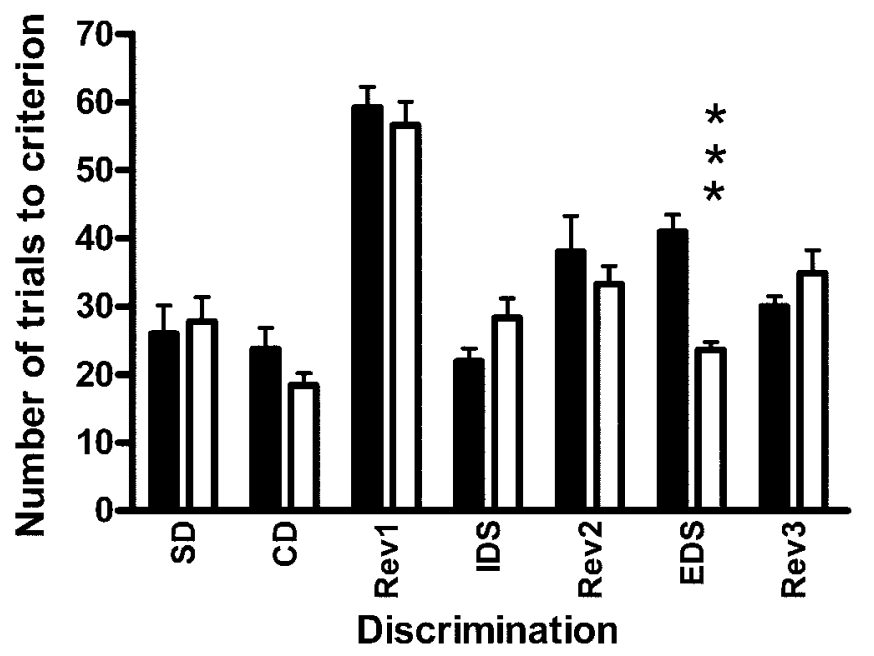

Figure 1. Effect of tolcapone on set-shifting trials to criterion. Vehicle (closed bars; $n=10$ ) or $30 \mathrm{mg} / \mathrm{kg}$ tolcapone (open bars; $n=10$ ) was administered $1 \mathrm{hr}$ before the start of the task. Tolcapone-treated animals performed significantly better on the EDS stage of the task $\left(^{*} p<\right.$ 0.001). There was no significant effect of tolcapone on simple discrimination (SD), compound discrimination (CD), intradimensional shift (IDS), or any of the reversal stages (Rev1-3).

Effect of COMT inhibition on baseline MPFC catecholamines COMT was inhibited in $\mathrm{mPFC}$ by $30 \mathrm{mg} / \mathrm{kg}$ tolcapone, as indexed by the accumulation of [DOPAC] $]_{\mathrm{EX}}$ (to $205 \%$ of baseline; $F_{(1,12)}=23.1 ; p<0.001$ ) and depletion of $[\mathrm{HVA}]_{\mathrm{EX}}$ (to $24 \%$ of baseline; $\left.F_{(1,12)}=27.4 ; p<0.001\right)$. Inhibition of COMT was maximal at $2 \mathrm{hr}$ (data not shown). Despite this inhibition, tolcapone administration had no effect on $[\mathrm{DA}]_{\mathrm{EX}}(F<1)($ Fig. $2 C)$ or $[\mathrm{NE}]_{\mathrm{EX}}\left(F_{(1,11)}=1.1 ; p>0.1\right)($ Fig. $2 D)$.

\section{Effect of COMT inhibition on MPFC catecholamines under} conditions of evoked catecholamine release

Administration of $10 \mathrm{mg} / \mathrm{kg}$ clozapine alone elevated $[\mathrm{DA}]_{\mathrm{EX}}$ at trend level (LSD; $p<0.1$ ) (Fig. $2 A, C$ ) and elevated [NE] $]_{\mathrm{EX}}$ (LSD; $p<0.05$ ) (Fig. $2 B, D$ ). Pretreatment with $30 \mathrm{mg} / \mathrm{kg}$ tolcapone significantly potentiated the increase in $[\mathrm{DA}]_{\mathrm{EX}}$ (LSD; $p<0.01$ compared with clozapine alone and $p<0.0001$ compared with control group) (Fig. $2 A, C$ ) but not $[\mathrm{NE}]_{\mathrm{EX}}$ (LSD; $p>0.1 \mathrm{com}$ pared with clozapine alone) (Fig. $2 B, D$ ). Overall, there was a significant effect of drug treatment on $[\mathrm{DA}]_{\mathrm{EX}}\left(F_{(2,17)}=15.1 ; p<\right.$ $0.0001)$ (Fig. $2 A, C)$ and a trend effect on $[\mathrm{NE}]_{\mathrm{EX}}\left(F_{(2,17)}=3.5\right.$; $p<0.1$ ) (Fig. $2 B, D$ ).

Local depolarization with potassium chloride $(56 \mathrm{~mm})$ elevated both $[\mathrm{DA}]_{\mathrm{EX}}\left(F_{(1,6)}=5.7 ; p<0.01\right)$ (Fig. $\left.2 E\right)$ and $[\mathrm{NE}]_{\mathrm{EX}}$ $\left(F_{(1,6)}=11.8 ; p<0.001\right)$ (Fig. $\left.2 F\right)$. Tolcapone pretreatment potentiated this elevation of $[\mathrm{DA}]_{\mathrm{EX}}\left(F_{(1,12)}=7.4 ; p<0.05\right)$ (Fig. $2 E)$ but not $[\mathrm{NE}]_{\mathrm{EX}}(F<1)$ (Fig. $\left.2 F\right)$.

\section{Discussion}

We have demonstrated that inhibition of COMT significantly and specifically improves performance on ED shifting, which is known to be mediated by catecholamines (Downes et al., 1989; Roberts et al., 1994; Middleton et al., 1999; Rogers et al., 1999; Ragozzino, 2002; Crofts et al., 2001) and to depend on the mPFC in rats (Birrell and Brown, 2000; Reid et al., 2003) and the PFC in primates (Dias et al., 1996a,b; Rogers et al., 2000; Manes et al., 2002). We also demonstrated a potential neurochemical mechanism for this effect, showing that COMT inhibition elevates $[\mathrm{DA}]_{\mathrm{EX}}$, but not $[\mathrm{NE}]_{\mathrm{EX}}$, in $\mathrm{mPFC}$ under conditions of evoked catecholamine release. Hence our data show that COMT activity
A
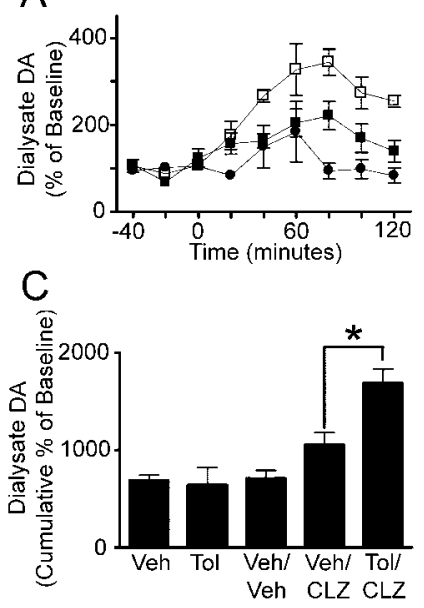

$\mathrm{E}$

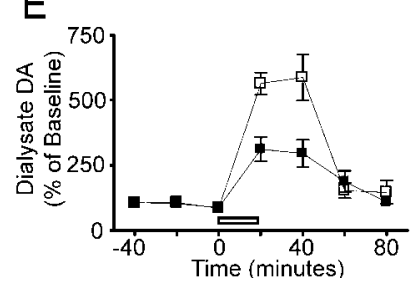

B
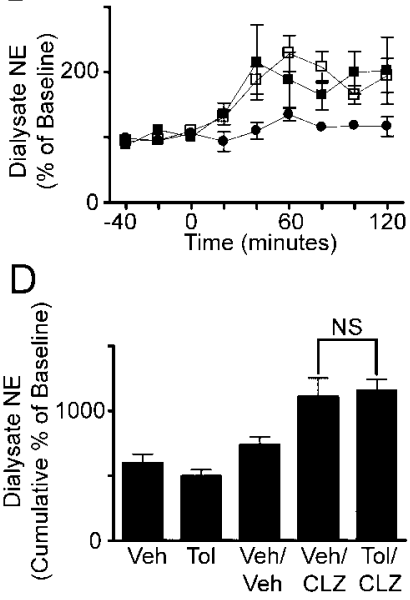

$\mathrm{F}$

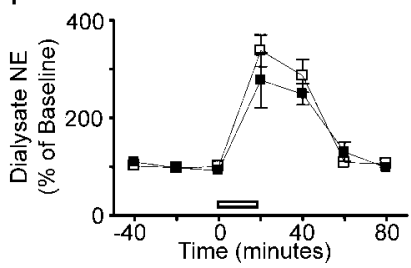

Figure 2. Effect of tolcapone on stimulated levels of $D A(A, C, E)$ and $N E(B, D, F)$. Tolcapone (30 mg/kg) (open symbols) or vehicle (closed symbols) was administered $2 \mathrm{hr}$ before drug challenge. Mean basal $[\mathrm{DA}]_{\mathrm{EX}}$ and $[\mathrm{NE}]_{\mathrm{EX}}$ levels were 15 and $80 \mathrm{fmol}$ per sample, respectively. $A$, $B$, Clozapine $(10 \mathrm{mg} / \mathrm{kg})$ (at time 0 ; closed squares; $n=8$ ) elevated [DA] $]_{\mathrm{EX}}(A)(p<0.01)$ and $[\mathrm{NE}]_{\mathrm{EX}}(B)(p<0.001)$ levels compared with vehicle (closed circles; $\left.n=6\right)$. Tolcapone pretreatment (open squares; $n=7)$ significantly potentiated this rise in $[D A]_{\mathrm{EX}}(A)(p<0.001)$ but not $[N E]_{\mathrm{EX}}(B)(p>0.1)$. The effect of tolcapone (Tol) or vehicle (Veh) administration on both basal and clozapine (CLZ)-induced $[D A]_{\mathrm{EX}}(\mathrm{C})$ and $[\mathrm{NE}]_{\mathrm{EX}}(D)$ for $2 \mathrm{hr}$ after drug challenge is shown with the significant increase in $[\mathrm{DA}]_{\mathrm{EX}}$ indicated with an asterisk. E, F, Tolcapone (open squares; $n=8$ ) or vehicle (closed squares; $n=8$ ) was administered $2 \mathrm{hr}$ before potassium challenge. High potassium artificial CSF was perfused through the microdialysis probe for 20 min, starting at 0 min as indicated by the open bar. Tolcapone pretreatment significantly potentiated the potassium-induced rise in $[\mathrm{DA}]_{\mathrm{EX}}(E)(p<0.01)$ but not $[\mathrm{NE}]_{\mathrm{EX}}(F)(p>0.1)$.

modulates set shifting and that this modulation is likely to be dependent on DA in $\mathrm{mPFC}$, although other cortical and subcortical regions (e.g., nucleus accumbens) may participate as well (Fox et al., 2003).

The improvement in ED shifting ability after COMT inhibition is reminiscent of human data in which the low-activity Met ${ }^{158}$ COMT allele is linked with better performance and greater "efficiency" on comparable tests of PFC function (Egan et al., 2001). Acute COMT inhibition is clearly not a perfect model of the human $\mathrm{Val}^{158}$ Met polymorphism, which may well be of a different magnitude and presumably affects COMT activity throughout life. The similarity, however, between our data and those linking the human polymorphism with behavior suggests that tolcapone administration is at least a partial simulation of COMT activity differences caused by the human polymorphism. Furthermore, our findings support the conclusion that the behavioral correlates of the $\mathrm{Val}^{158} \mathrm{Met}$ polymorphism are indeed caused by genetic variation in COMT and not by alterations at a separate genetic locus in linkage disequilibrium with the polymorphism.

The data show that COMT is important for modulating mPFC DA under stimulated but not basal conditions. This suggests strongly that COMT activity may be important specifically under conditions of increased catecholamine efflux, as would 
reasonably be expected during task performance (Watanabe et al., 1997; Wilkinson et al., 1998). These data parallel findings in striatum, in which tolcapone pretreatment has been found to elevate $[\mathrm{DA}]_{\mathrm{EX}}$, but only after a pharmacological challenge (Acquas et al., 1992). It is also interesting that tolcapone pretreatment modulates $[\mathrm{DA}]_{\mathrm{EX}}$ but not $[\mathrm{NE}]_{\mathrm{EX}}$, because COMT has similar affinities for both substrates (Lotta et al., 1995). Although puzzling, there are precedents for this differential effect. The data are reminiscent of those obtained in the COMT knock-out mouse, in which the males show elevated frontal DA but not NE (Gogos et al., 1998) and after depletion of the catecholamine precursor tyrosine, which interferes with central DA but not NE function (McTavish et al., 1999). This sensitivity of DA but not $\mathrm{NE}$ to COMT inhibition is unexplained. It may relate to a differential accessibility of DA and NE to COMT, but this remains speculative until the cellular and subcellular location of the enzyme (both membrane-bound and soluble forms) is resolved (Ulmanen et al., 1997; Matsumoto et al., 2003).

A final implication of our data relates to the treatment of schizophrenia. It has been suggested that the putative amelioration of cognitive symptoms by atypical antipsychotics such as clozapine and olanzapine may be related to activation of DA neurons and increased release of DA in the mPFC (Moghaddam and Bunney, 1990; Meltzer and McGurk, 1999). If so, our finding that tolcapone augments the clozapine-induced increase in mPFC DA release suggests that these therapeutic effects may be modified by coadministration with a brain-penetrant COMT inhibitor. This could either be used to enhance the increase in cortical DA, toward the peak of the hypothesized inverted U-shaped relationship with PFC performance (Mattay et al., 2003), or permit a lower dose of clozapine to be used. The combined effect of clozapine and tolcapone on set shifting cannot be determined from the results of this study. Recent evidence, however, supports the view that COMT activity, as reflected in the $\mathrm{Val}^{158}$ Met genotype, may indeed predict cognitive and PFC response to atypical antipsychotics (Bertolino et al., 2003).

In conclusion, we have demonstrated improvement of $\mathrm{ED}$ shifting in rats treated with a COMT inhibitor. Additionally, we have shown that COMT affects MPFC DA, but not NE, under conditions that likely pertain during task performance. These studies emphasize the role of COMT in DA modulation of PFC function. Finally, our data also suggest potential benefits of COMT inhibition as an adjunct in the treatment of cognitive impairment in schizophrenia.

\section{References}

Acquas E, Carboni E, de Ree RHA, Da Prada M, Di Chiara G (1992) Extracellular concentrations of dopamine and metabolites in the rat caudate after oral administration of a novel catechol-O-methyltransferase inhibitor Ro 40-7592. J Neurochem 59:326-330.

Bertolino A, Caforio G, Blasi G, De Candia M, Latorre V, Petruzzella V, Altamura M, Nappi G, Papa S, Callicot JH, Mattay VS, Bellomo A, Scarabino T, Weinberger DR, Nardini M (2003) Differential effect of COMT Val108/158 Met genotype on enhancement of prefrontal cortical function and working memory in patients with schizophrenia treated with olanzapine. Soc Neurosci Abstr 29:881.5.

Birrell J, Brown VJ (2000) Medial frontal cortex mediates perceptual attentional set shifting in the rat. J Neurosci 20:4320-4324.

Ceravolo R, Piccini P, Bailey DL, Jorga KM, Bryson H, Brooks DJ (2002) ${ }^{18} \mathrm{~F}$-Dopa PET evidence that tolcapone acts as a central COMT inhibitor in Parkinson's disease. Synapse 43:201-207.

Crofts HS, Dalley JW, Collins P, Van Denderen JCM, Everitt BJ, Robbins TW, Roberts AC (2001) Differential effect of 6-OHDA lesions of the frontal cortex and caudate nucleus on the ability to acquire an attentional set. Cereb Cortex 11:1015-1026.

Dias R, Robbins TW, Roberts AC (1996a) Primate analogue of the Wiscon- sin card sorting test: effects of excitotoxic lesions of the prefrontal cortex in the marmoset. Behav Neurosci 110:872-876.

Dias R, Robbins TW, Roberts AC (1996b) Dissociation in prefrontal cortex of affective and attentional shifts. Nature 380:69-72.

Downes JJ, Roberts AC, Sahakian BJ, Evenden JL, Morris RG, Robbins TW (1989) Impaired extra-dimensional shift performance in medicated and unmedicated Parkinson's disease: evidence for a specific attentional dysfunction. Neuropsychologia 27:1329-1343.

Egan MF, Goldberg TE, Kolachana BS, Callicot JH, Mazzanti CM, Straub RE, Goldman D, Weinberger DR (2001) Effect of COMT Val ${ }^{108 / 158}$ Met genotype on frontal lobe function and risk for schizophrenia. Proc Natl Acad Sci USA 98:6917-6922.

Fox MT, Barense MD, Baxter MG (2003) Perceptual attentional set-shifting is impaired in rats with neurotoxic lesions of posterior parietal cortex. J Neurosci 23:676-681.

Gaspirini M, Fabrizio E, Bonifati V, Meco G (1997) Cognitive improvement during tolcapone treatment in Parkinson's disease. J Neural Transm 104:887-894.

Gogos JA, Morgan M, Luine V, Santha M, Ogawa S, Pfaff D, Karayiorgou M (1998) Catechol-O-methlytransferase-deficient mice exhibit sexually dimorphic changes in catecholamine levels and behaviour. Proc Natl Acad Sci USA 95:9991-9996.

Khromova I, Voronina T, Kraineva VA, Zolotov N, Männisto PT (1997) Effect of selective catechol-O-methyltransferase inhibitor on single-trial passive avoidance retention in male rats. Behav Brain Res 86:49-57.

Lachman HM, Papolos DF, Saito T, Yu Y-M, Szumlanski CL, Weinshilboum RM (1996) Human catechol-O-methlytransferase pharmacogenetics: description of a functional polymorphism and its potential application to neuropsychiatric disorders. Pharmacogenetics 6:243-250.

Liljequist R, Haapalinna A, Åhlander M, Li YH, Männisto PT (1997) Catechol-O-methyltransferase inhibitor tolcapone has minor influence on performance in experimental memory models in rats. Behav Brain Res 82:195-202.

Lotta T, Vidgren J, Tilgmann C, Ulmanen I, Melén K, Julkunen I, Taskinen J (1995) Kinetics of human soluble and membrane-bound catechol-Omethyltransferase: a revised mechanism and description of the thermolabile variant of the enzyme. Biochemistry 34:4202-4210.

Manes F, Sahakian B, Clark L, Rogers R, Antoun N, Aitken M, Robbins T (2002) Decision-making processes following damage to the prefrontal cortex. Brain 125:624-639.

Männisto PT, Kaakkola S (1999) Catechol-O-methyltransferase (COMT): biochemistry, molecular biology, pharmacology, and clinical efficacy of the new selective COMT inhibitors. Pharmacol Rev 51:593-628.

Matsumoto M, Weickert CS, Akil M, Lipska BK, Hyde TM, Herman MM, Weinberger DR, Kleinman JE (2003) Catechol-O-methyltransferase mRNA expression in human and rat brain: evidence for a role in cortical neuronal function. Neuroscience 116:127-137.

Mattay VS, Goldberg TE, Fera F, Hariri AR, Tessitore A, Egan MF, Kolachana B, Callicott JH, Weinberger DR (2003) Catechol-O-methyltransferase val158-met genotype and individual variation in the brain response to amphetamine. Proc Natl Acad Sci USA 100:6186-6191.

McTavish SFB, Callado L, Cowen PJ, Sharp T (1999) Comparison of the effects of $\alpha$-methyl-p-tyrosine and a tyrosine-free amino acid load on extracellular noradrenaline in the rat hippocampus in vivo. J Psychopharmacol 13:379-384.

Meltzer HY, McGurk SR (1999) The effects of clozapine, risperidone, and olanzapine on cognitive function in schizophrenia. Schizophr Bull 25:233-255.

Middleton HC, Sharma A, Agouzoul D, Sahakian BJ, Robbins TW (1999) Idazoxan potentiates rather than antagonizes some of the cognitive effects of clonidine. Psychopharmacology (Berl) 145:401-411.

Moghaddam B, Bunney BS (1990) Acute effects of typical and atypical antipsychotic drugs on the release of dopamine from prefrontal cortex, nucleus accumbens, and striatum of the rat: an in vivo microdialysis study. J Neurochem 54:1755-1760.

Nagahama Y, Okada T, Katsumi Y, Hayashi T, Yamauchi H, Oyanagi C, Konishi J, Fukuyama H, Shibasaki H (2001) Dissociable mechanisms of attentional control within the human prefrontal cortex. Cereb Cortex 11:85-92.

Paxinos G, Watson C (1986) The rat brain in stereotaxic coordinates. San Diego: Academic.

Ragozzino ME (2002) The effects of dopamine D1 receptor blockade in the 
prelimbic-infralimbic areas on behavioural flexibility. Learn Mem 9:18-28.

Reid L, Egerton A, Morris BJ, Pratt A (2003) Acute PCP administration produces an attention set shifting deficit and reduced neural activity in the medial frontal cortex of the rat. Soc Neurosci Abstr 29:940.11.

Roberts AC, Robbins TW, Everitt BJ (1988) Extra-dimensional versus intradimensional set shifting performance following frontal lobe excisions, temporal lobe excisions or amygdalo-hippocampectomy in man. Neuropsychologia 29:993-1006.

Roberts AC, De Salvia MA, Wilkinson LS, Collins P, Muir JL, Everitt BJ, Robbins TW (1994) 6-Hydroxydopamine lesions of the prefrontal cortex in monkeys enhance performance on an analog of the Wisconsin card sort test: possible interaction with subcortical dopamine. J Neurosci 4:2531-2544.

Rogers RD, Blackshaw AJ, Middleton HC, Matthews K, Hawtin K, Crowley C, Hopwood A, Wallace C, Deakin JF, Sahakian BJ, Robbins TW (1999) Tryptophan depletion impairs stimulus-reward learning while methylphenidate disrupts attentional control in healthy young adults: implications for the monoaminergic basis of impulsive behaviour. Psychopharmacology (Berl) 146:482-491.

Rogers RD, Andrews TC, Grasby PM, Brooks DJ, Robbins TW (2000) Contrasting cortical and subcortical activations produced by attentional-set shifting and reversal learning in humans. J Cognit Neurosci 12:142-162.

Sesack SR, Hawrylak VA, Matus C, Guido MA, Levey AI (1998) Dopamine axon varicositites in the prelimbic division of the rat prefrontal cortex exhibit sparse immunoreactivity for the dopamine transporter. J Neurosci 18:2697-2708.
Shifman S, Bronstein M, Strenfeld M, Pisanté-Shalom A, Lev-Lehman E, Weizman A, Reznik I, Spivak B, Grisaru N, Karp L, Schiffer R, Kotler M, Strous RD, Swartz-Vanetik M, Knobler HY, Shinar E, Beckmann JS, Yakir B, Risch N, Zak NB, Darvasi A (2002) A highly significant association between a COMT haplotype and schizophrenia. Am J Hum Genet 71:1296-1302.

Ulmanen I, Peränen J, Tenhunen J, Tilgmann C, Karhunen T, Panula P, Bernasconi L, Aubry JP, Lundstrom K (1997) Expression and intracellular localization of catechol-O-methyltransferase in transfected mammalian cells. Eur J Biochem 243:452-459.

Watanabe M, Kodama T, Hikosaka K (1997) Increase of extracellular dopamine in primate prefrontal cortex during a working memory task. J Neurophysiol 78:2795-2798.

Wilkinson LS, Humby T, Killcross AS, Torres EM, Everitt BJ, Robbins TW (1998) Dissociations in dopamine release in medial prefrontal cortex and ventral striatum during the acquisition and extinction of classical aversive conditioning in the rat. Eur J Neurosci 10:1019-1026.

Williams GV, Goldman-Rakic PS (1995) Modulation of memory fields by dopamine D1 receptors in prefrontal cortex. Nature 376:572-574.

Zahrt J, Taylor JR, Mathew RG, Arnsten AFT (1997) Supranormal stimulation of D1 dopamine receptors in the rodent prefrontal cortex impairs working memory performance. J Neurosci 17:8528-8535.

Zürcher G, Keller HH, Kettler R, Borgulya J, Bonetti EP, Eigenmann R, Da Prada M (1990) Ro 40-7592, a novel, very potent, and orally active inhibitor of catechol-O-methyltransferase: a pharmacological study in rats. Adv Neurol 53:497-503. 